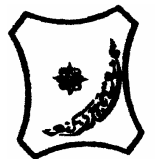

Bayero Journal of Pure and Applied Sciences, 4(2): 109 - 117

Received: June, 2011

Accepted: September, 2011

ISSN $2006-6996$

\title{
QUALITATIVE INVESTIGATION OF SOME LOCALLY PRODUCED PRINTED FABRICS AND FOREIGN PRINTED FABRICS MARKETED IN NIGERIA
}

\author{
*M. B. Musa, M. K. Yakubu, and E. Danfulani \\ Department of Textile Science \& Technology, Ahmadu Bello University, Zaria, Nigeria \\ *Correspondence author: mmbukharisal@yahoo.co.uk
}

\begin{abstract}
Qualitative analysis of some selected locally produced fabrics and foreign fabrics marketed in Nigeria was carried out. The comparative study of the Physico - mechanical properties of the fabrics were made. The results obtained showed that the locally produced fabrics exhibited comparably better end - use performance characteristics in terms of fabric weight per square meter, fabric flammability, and linear density. While the foreign fabrics are better in terms of Crease recovery, fabric handle, fabric sett, fabric shrinkage, and aesthetics. However, both the foreign and homemade fabrics exhibited similar characteristics in terms of abrasion resistance, tensile strength, air permeability, yarn crimp, fabric thickness, and colour fastness.

Keywords; foreign-fabrics, home-made fabrics, quality characteristics.
\end{abstract}

INTRODUCTION

Nigerian people generally prefer foreign (textile) goods over the homemade materials. This is because of the belief that the performance properties of the foreign made textiles are better than those produced locally (Raji et al., 2007).

The quality (value) of a textile material is often determined by the feel (handle), aesthetic properties, comfortability during use, serviceability and probably past experience.

This study is a comparative analysis between some local wax printed textile product and their foreign counterparts marketed in Nigeria bearing in mind their

technical properties which give rise to the market values.

The overall objective of this work is to determine the basis or other wise for the Nigerian's preference of foreign goods over locally made materials from technical point of view.

\section{MATERIALS AND METHODS}

Six materials were analysed, three foreign textiles and three locally produced goods. All the fabrics are cotton materials, containing staple length of fibres of about 1 inch. The test materials are throughout the work referred to as ; I, II, III, IV, V, VI. Thus;-

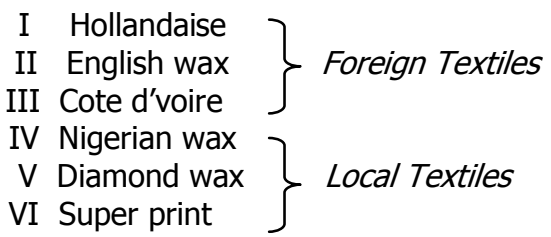

\section{Instruments/ Equipment}

Shirley air permeability tester, Martindale wear Abrasion tester, Shirley Crease recovery instrument, Cussicle drape tester, Shirley Crimp tester, Essdiel Thickness gauge, Instron tester model 1026, Digital weighing balance, Grey scale for assessing change in colour, Grey scale for assessing stain, Microscopic lens, Beakers, Stop watch, Counting glass, Stirring rods, Bunsen burner, Meter rule, Scissors, Dissecting needle, Thermometer.

\section{Fabric Testing}

The six samples were evaluated for those properties required for satisfactory end use performance as apparel fabric. All the tests were carried out in accordance with the British standard hand book II (1974), after conditioning the fabrics in an atmosphere of $65 \%$ relative humidity $(\mathrm{RH})$ and Temperature of $20 \pm 2^{\circ} \mathrm{C}$ for at least 48 hours.

\section{Air Permeability}

The air permeability test of the samples was carried out in accordance with the British Standard Hand book II (1974). The apparatus used was the Shirley air permeability tester. For each sample, six tests were carried out on different portions. The test area was $5.02 \mathrm{~cm}^{2}$ and at the pressure head of $10 \mathrm{~mm}$ of water. The air permeability was obtained using the following formula;

Fabric air permeability $=\underline{\text { mean } \text { rota meter reading }}$

$$
\text { Test area }
$$

The average values of the rotameter readings was calculated and the average volume of air and the air resistance was calculated and used for Figure 1. 


\section{Abrasion Resistance}

The abrasion resistance test of each sample was carried out using the break method as outlined in the British Standard Hand book II (1974). Using the Martindale abrasion tester. The average loss in weight per 10,000 rubs was obtained and the reciprocal of percentage loss in weight was used as the resistance to Abrasion. The result is shown in Figure 3.

\section{Crease Recovery}

This test was carried out in accordance with the British Standard Hand book II (1974) with the aid of Shirley Crease recovery Instrument. 12 rectangular strips of $5 \mathrm{~cm} \times 2.5 \mathrm{~cm}$ dimensions were cut from each of the sample in both weft and warp directions. The Creasing load was 20 Newton for 60 seconds, the results is shown in Figure 4

\section{Fabric Handle}

The pieces of the six different samples were given to about 30 people to comment on the feel and physical appearance. Their views were compared and used to determine the fabric handle and visual assessment.

\section{Fabric Drape}

Two fabric pieces $30 \mathrm{~cm}$ diameter each were cut out from each sample and tested for drape characteristics on a Cussick drape tester according to British Standard 5058 specification. The fabric pieces were allowed to hang under the action of gravity, then the shadow of the fabric on the ring paper was traced out. The weight of the ring Paper $\left(\mathrm{M}_{2}\right)$ was determined. The outline was traced and then cut and the inner part weighed to give $\left(M_{1}\right)$. Two tests were carried out for each fabric at different places and the average values of $M_{1}$ and $M_{2}$ were obtained. The drape coefficient was therefore calculated thus:

Drape coefficient $=M_{2} / M_{1} \times 100(\%)$

The values were used to obtain Figure 6

\section{Fabric Sett}

The $1 \mathrm{~cm}$ counting glass method as outlined in British Standard Hand book 11 (1974) was used. With this method, the number of warp and weft threads/centimeter for each fabric under analysis were determined by placing the glass on the fabric before counting. Twelve determinations were carried out on each sample and the mean values were calculated and recorded and shown in Table 3. .

\section{Yarn Crimp}

The test was carried out in accordance with British standard Hand book II (1974) using the Crimp tester and Dissecting pin. The fabrics were laid flat, free from tension and creases. A rectangular strip of about $20 \mathrm{~cm} \times 20 \mathrm{~cm}$ was marked out along the warp and weft directions, the yarn samples were carefully removed using a dissecting needle.

The yarns were tensioned as recommended, twenty readings were taken for each series of threads and the mean calculated. The percentage crimp was calculated as follows;

$\%$ Crimp $=$ Straightened yarn length - length of yarn in fabric $\times 100$ Length of yarn in fabric
The result obtained was used for Figure 2 .

\section{Fabric weight/ area}

The fabric was cut to a dimension of $10 \mathrm{~cm} \times 5 \mathrm{~cm}$ and weighed. The weight/square meter was then calculated and used for Figure 5

\section{Fabric flammability}

The vertical strip test principle was employed in this work. The test fabric was cut to a dimension of $4 \mathrm{~cm}$ $x 1 \mathrm{~cm}$ and was suspended in a drought free cabinet (where air does not flow freely) and held at the top end over the top most wire by clips. The flame from a candle stick was put below the lower end of the fabric. Using a stop watch, the time (seconds) it took the flame to consume the fabric from its lower to top end was noted and used for fabric flammability grading. The results for the six fabric samples were as shown in Table 5.

\section{Tensile Strength}

The Tensile strength test was carried out in accordance with British Standard Hand book II (1974), using the Instron model 1026. For each test fabric, five strips from warp and weft directions were cut out each of dimension $15 \mathrm{~cm} \times 15 \mathrm{~cm}$. Each sample was axially extended until it broke under the applied load. Two readings were taken and the mean values used for Figures 7 and 8.

\section{Fabric Thickness}

The test for fabric thickness was carried out in accordance with British Standard Hand book II (1974), the apparatus used was Essdiel Thickness gauge. Ten tests were carried out for each fabric and the mean value calculated, the standard deviation and coefficient of variation were also calculated and recorded in Table 2

\section{Yarn Count}

This was carried out in accordance with British Standard Hand book II (1974). The apparatus used was the Digital weighing Balance and Dissecting pin. Here $20 \mathrm{~cm} \times 20 \mathrm{~cm}$ strips of the samples were prepared from the fabrics under investigation. Five threads each from warp and weft directions were removed from the strips using the dissecting pin. The crimp of the yarn was removed by the crimp tester. The weight of each group was determined and this was used to calculate the yarn count as follows;

\section{Tex count $=W / L \times 100$}

Where $W=$ weight of yarns (grams)

$$
L=\text { Length (meters) }
$$

The results are shown in Table 4.

\section{Water Resistance}

The test for water resistance for the six fabric under study were carried out in accordance with British Standard Hand book II (1974). The test (sample) Fabric was mounted onto an embroidery hoop and placed to face upper most on the hoop support. $250 \mathrm{ml}$ of water contained in a beaker was poured onto the surface of the fabric inclined at an angle of $45^{\circ}$ through a funnel with tiny holes. The water was poured quickly and steadily to ensure a continuous flow of spraying once it has commenced. 
After the spraying from the funnel had stopped, the test fabric was tapped twice with a solid object with the fabric faced down in a horizontal position.

After the tapping, with the fabric still on the hoop, a spray rating was then assigned to the tested fabric by visually comparing the appearance of the sprayed sample with that of the nearest corresponding standard ratings given. The results were used for Table 6.

\section{Colour Fastness to washing}

The Colour fastness test for the six fabric (samples) under investigation were carried out in the linitest machine to the ISO recommendation No. 3. The test specimen of dimension $5 \mathrm{~cm} \times 4 \mathrm{~cm}$ was placed between two specified pieces of undyed cloth of dimension $10 \mathrm{~cm} \times 5 \mathrm{~cm}$. The three pieces were stitched together to form a composite. The composite specimen was placed in a container containing $5 \mathrm{~g} / \mathrm{L}$ soap and $2 \mathrm{~g} / \mathrm{l} \mathrm{Na} \mathrm{CO}_{3}$ solution previously heated to a temperature of $60 \pm 2^{\circ} \mathrm{C}$, so as to give a liquor ratio of 50:1. The composite specimen was removed, rinsed and assessed. Assessment of change in colour of the specimen and the staining of the adjacent fabric was carried out using a Grey scale fatness rating of the samples, the result obtained was shown in Table 7.

\section{Fabric Shrinkage}

The specimen was conditioned and a pen was used to mark out the dimensions of $10 \mathrm{~cm} \times 10 \mathrm{~cm}$. The sample was immersed in a trey of $10 \mathrm{~cm}^{3}, 2 \mathrm{~cm}$ deep containing water at room temperature. The specimens were submerged in boiling water for 2 hours and were carefully removed and each laid on a piece of glass dabbed with an absorbent cloth so as to remove excess water. It was then allowed to dry naturally. After being thoroughly dried, the dimensions were measured for each sample and the \% shrinkage for warp and weft directions were calculated and recorded in Table 1

\section{RESULTS AND DISCUSSION Air Permeability}

Air permeability affects the comfort properties of a garment in terms of air passage across the fabric. Too high air permeability per unit area of a fabric gives lower protection against winds especially for outer wear garments, while too low air permeability affect body perspiration (Danfulani, 2006).
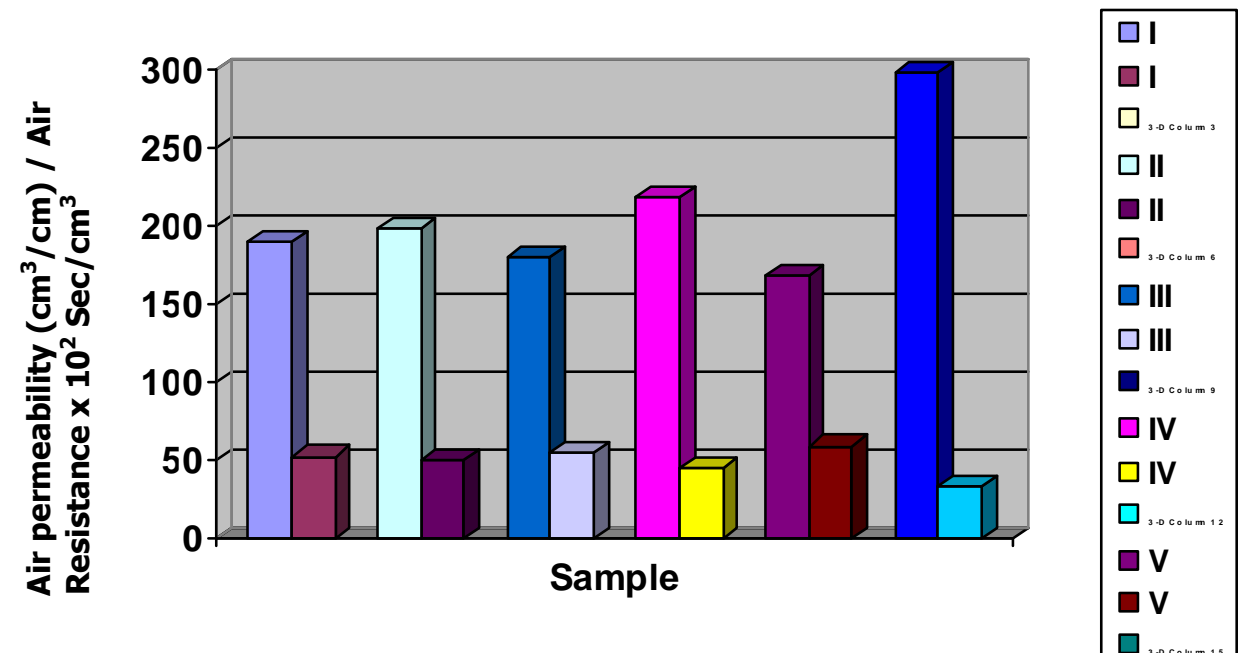

\section{Figure 1: Air Permeability}

Figure 1 showed that the air permeability of samples I, II, III, IV, V are at close range with sample VI having the highest value and sample $\mathrm{V}$ the lowest, hence the foreign fabrics in between them.

The large number of opening per unit area of sample VI is as a result of its construction for a relatively lower quality material.

It has generally been demonstrated that air permeability decreases as thickness, weight or fabric density increase (Omar, 2006). This is in agreement with the result comparing Figure1, Tables 2 and 3, and Figure 5.

\section{Yarn Crimp}

It may be observed from Figure 2 that the weft crimp is generally higher than the warp crimp as expected. This is due to the fact that the warp yarn was under greater tension during weaving process on the loom as compared to the weft yarn. So also the weft yarn was more flexible relative to the stiffer warp yarn which was coated with size so as to withstand tension and frictional effects of the healds during weaving action.

The crimp of samples I, II, \& V are higher given the fabrics a fuller and more compressible feel. It must be noted that sample $\mathrm{V}$ was deliberately produced to simulate foreign fabrics, thus its ability to compete favorably in this property with the foreign materials. 

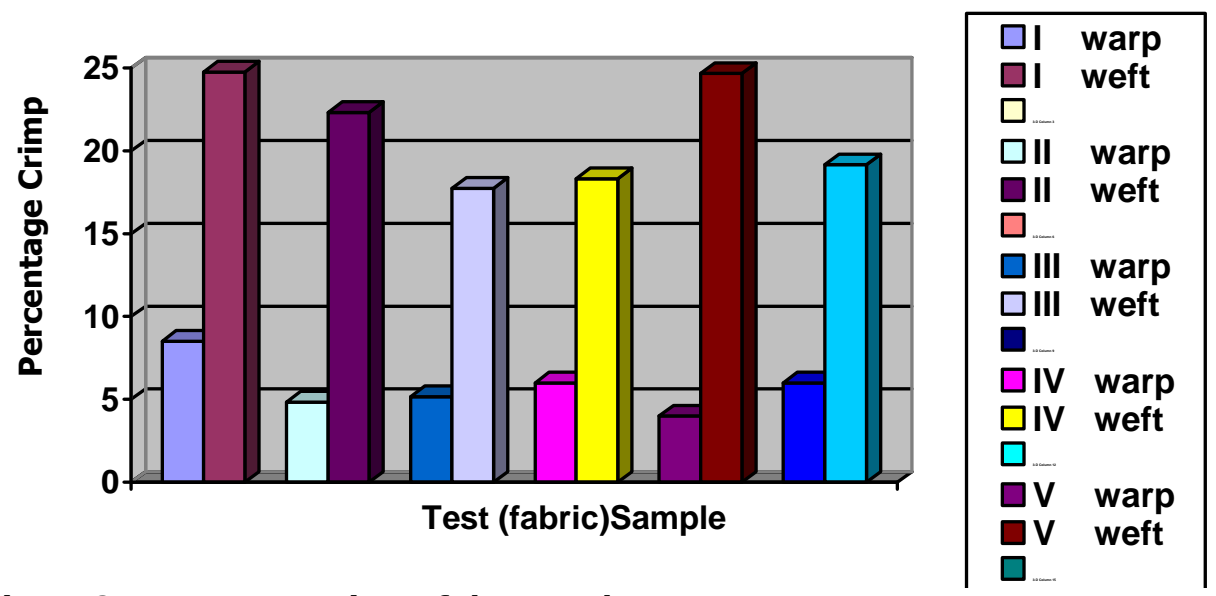

Figure 2: percentage crimp of the samples

\section{Abrasion Resistance}

Abrasion resistance is a parameter which is related to rubbing action, which affects the durability, and also its performance characteristics. The assessment of abrasion of fabrics, usually provides the fabrics with conditions similar to those it will be subjected to, while in use.

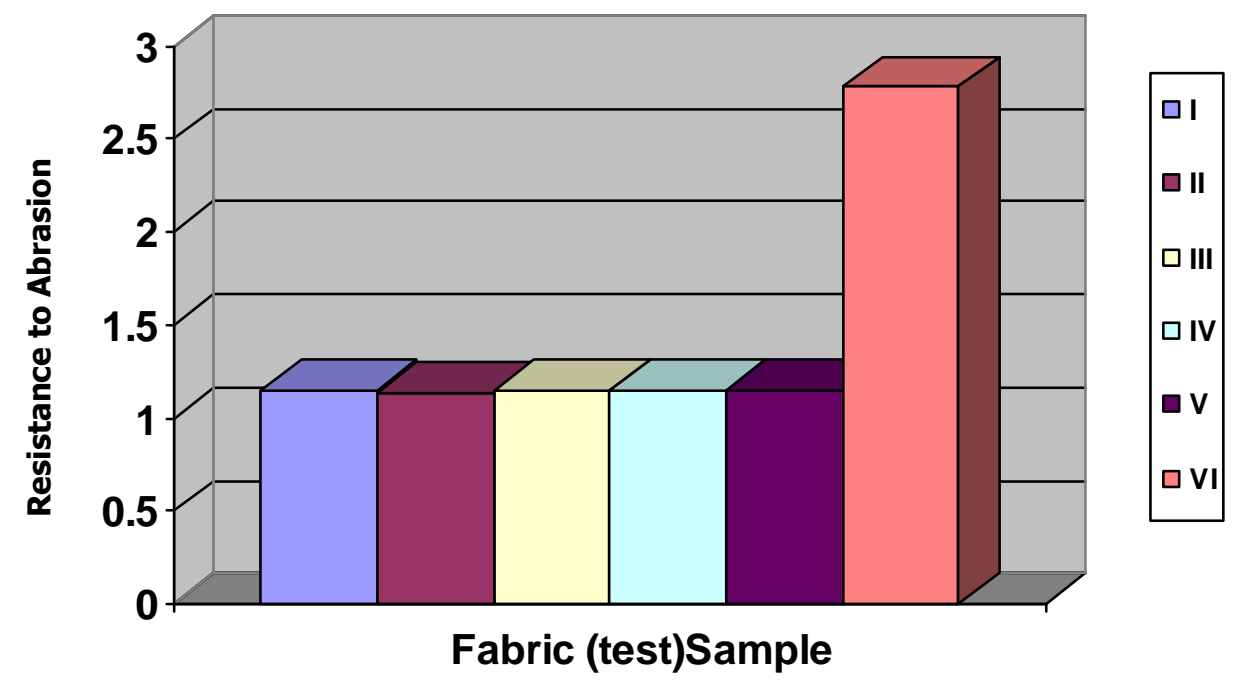

Figure 3: Abrasion resistance

The results obtained in this work is very remarkable (figure 3), as it indicates that all the wax materials (foreign and local) exhibit similar abrasion resistance, thus it will be expected that under same conditions of usage samples I, II, III, IV, and V will be equally durable.

The high abrasion resistance for sample VI may be attributed to the class of its consumers, as this class will tend to persistently use a particular garment for a very long period of time.

\section{Fabric Shrinkage}

The percentage shrinkage of a fabric is an indication of its dimensional stability.

Table 1: \%Fabric Shrinkage

\begin{tabular}{|c|c|c|c|c|c|c|c|}
\hline $\begin{array}{l}\text { TEST } \\
\text { SAMPLE }\end{array}$ & $\begin{array}{l}\text { WEFT } \\
\text { Initial length } \\
(\mathbf{c m}) \\
\end{array}$ & $\begin{array}{l}\text { Final } \\
(\mathrm{cm})\end{array}$ & length & $\begin{array}{c}\text { Shrinkage } \\
(\%)\end{array}$ & $\begin{array}{l}\text { WARP } \\
\text { Initial length } \\
(\mathrm{cm})\end{array}$ & $\begin{array}{l}\text { Final } \\
(\mathrm{cm})\end{array}$ & $\begin{array}{c}\text { Shrinkage } \\
(\%)\end{array}$ \\
\hline $\mathrm{I}$ & 10.00 & 9.80 & & 2.0 & 10.00 & 9.70 & 3.0 \\
\hline II & 10.00 & 9.70 & & 3.0 & 10.00 & 10.00 & 0.0 \\
\hline III & 10.00 & 10.00 & & 0.0 & 10.00 & 10.00 & 0.0 \\
\hline IV & 10.00 & 9.50 & & 5.0 & 10.00 & 9.50 & 5.0 \\
\hline V & 10.00 & 9.90 & & 1.0 & 10.00 & 9.85 & 1.5 \\
\hline VI & 10.00 & 9.80 & & 2.0 & 10.00 & 9.60 & 4.0 \\
\hline
\end{tabular}


Table 1 indicates that sample IV had the highest \% shrinkage in both warp and weft directions. While sample III had no shrinkage in both warp and weft directions, and sample II had zero shrinkage in the warp direction. It can be inferred that the foreign fabrics were dimensionally more stable.

\section{Crease Recovery}

Those materials which recovered best from creasing in both warp and weft directions, have good easy care properties and do not require much ironing before use (Danfulani, 2006).

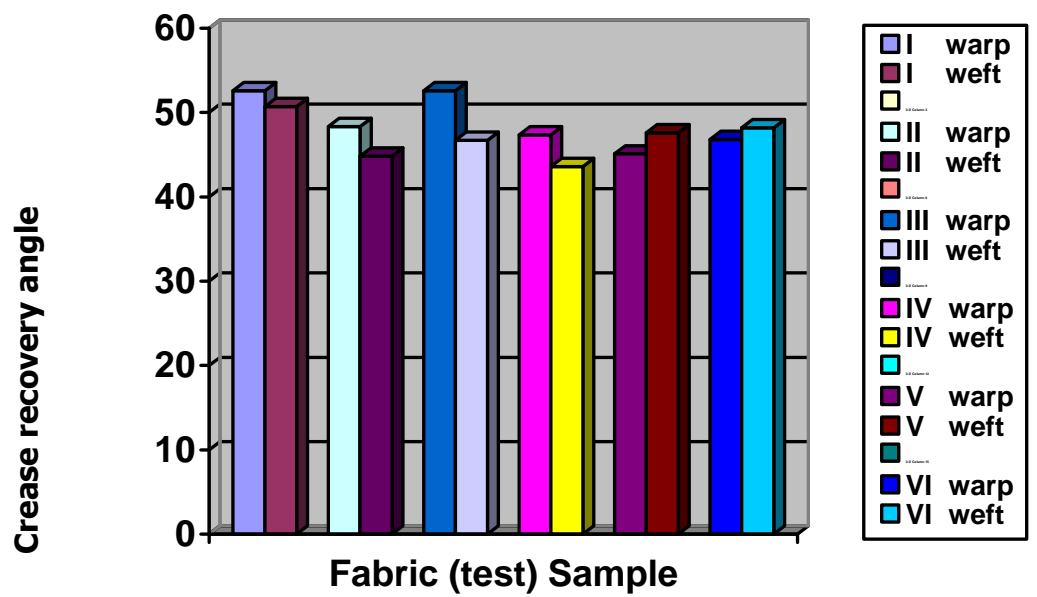

Figure 4: Crease recovery

Figure 4 showed that, the foreign fabrics have better crease recovery properties with sample I having the highest Crease recovery angle in both warp and weft directions, and sample IV the lowest.

\section{Fabric Thickness}

The thickness of a fabric depends on the mass/unit area, fabric (sett) density, and the nature (count) of yarns used. Various properties such as abrasion resistance, dimensional stability, stiffness and thermal insulation are affected by fabric thickness (Danfulani, 2006).

Table 2: Fabric thickness

\begin{tabular}{clll}
\hline TEST SAMPLE & $\begin{array}{c}\text { MEAN THICKNESS (X103) } \\
(\mathbf{m m})\end{array}$ & $\begin{array}{c}\text { STANDARD DEVIATION } \\
\text { S. } \boldsymbol{D}\end{array}$ & $\begin{array}{c}\text { COEFFICIENT OF VARIATION } \\
\boldsymbol{C} . \boldsymbol{V}(\boldsymbol{\%})\end{array}$ \\
\hline I & 2.856 & 0.093 & 3.26 \\
II & 2.658 & 0.049 & 1.85 \\
III & 3.100 & 0.316 & 10.20 \\
IV & 3.046 & 0.103 & 3.38 \\
V & 3.048 & 0.143 & 4.70 \\
VI & 2.434 & 0.042 & 1.73 \\
\hline
\end{tabular}

It can be observed from Table 2 that, though sample (I) has the highest fabric thickness, the locally produced fabrics are generally thicker than the foreign fabrics.

\section{Fabric Sett}

The fabric density has a direct influence on the cover factor and may be dependent to a certain extent on the yarn count. It may also be related to the fabric handle and appearance especially in terms of fabric thickness (Danfulani, 2006).

Table 3: Fabric density

\begin{tabular}{|c|c|c|c|c|c|}
\hline TEST SAMPLE & $\begin{array}{l}\text { END } \\
(\mathrm{epcm})\end{array}$ & $\begin{array}{r}\text { PICKS } \\
\text { (ppcm) }\end{array}$ & PER & CENTMETER & epcm x ppcm \\
\hline I & 17 & 15 & & & 225 \\
\hline II & 16 & 14 & & & 224 \\
\hline III & 18 & 14 & & & 252 \\
\hline IV & 16 & 12 & & & 192 \\
\hline V & 19 & 16 & & & 304 \\
\hline VI & 14 & 11 & & & 154 \\
\hline
\end{tabular}


Table 3 showed that samples I, II, III, IV, \& V. have similar values of epcm and also samples I, II, III, \& V have very close ppcm. The low values of epcm \& ppcm for sample IV is as a result of the fact that it's construction was design for a relatively low quality material.

\section{Yarn Count}

The yarn count may affect the feel and the appearance of a fabric to a certain extent its durability in use. It may also be related to the fineness of the material in terms of use and comfort.

Table 4: Yarn Count (Tex)

\begin{tabular}{lclllll}
$\begin{array}{l}\text { TEST } \\
\text { SAMPLE }\end{array}$ & $\begin{array}{c}\text { WEAN } \\
\text { Mex }\end{array}$ & S.D & C.V \% & $\begin{array}{r}\text { WEFT } \\
\text { MEAN } \\
\text { Tex }\end{array}$ & S.D & C.V \% \\
\hline I & 23.05 & 2.6389 & 0.0012 & 20.90 & 0.0003 & 0.6330 \\
II & 24.55 & 3.0583 & 0.0015 & 20.50 & 0.0042 & 0.9813 \\
III & 24.35 & 0.9521 & 0.0005 & 20.80 & 0.0001 & 0.2404 \\
IV & 23.85 & 0.5547 & 0.0003 & 21.00 & 0.0001 & 0.5200 \\
V & 27.10 & .07718 & .0014 & 23.70 & 0.0013 & 0.7909 \\
VI & 21.60 & 0.6124 & .0003 & 21.20 & 0.0003 & 0.6876 \\
\hline
\end{tabular}

Key: CV = Coefficient of Variation, S.D. = Standard deviation

Table 4 showed that both the local and foreign fabric under investigation contain more or less the same kind of yarns in terms of yarn count for both warp and weft. Never the less sample $V$ has higher yarn count for both warp and weft which may be partly responsible for its higher stiffness as indicated in figure 6 .

\section{Fabric weight per square meter}

The area density of a fabric is a very important parameter as it gives an indication of the amount of material it contains. It is also related to the fineness of the material in terms of use and comfortability (Booth, 1974).

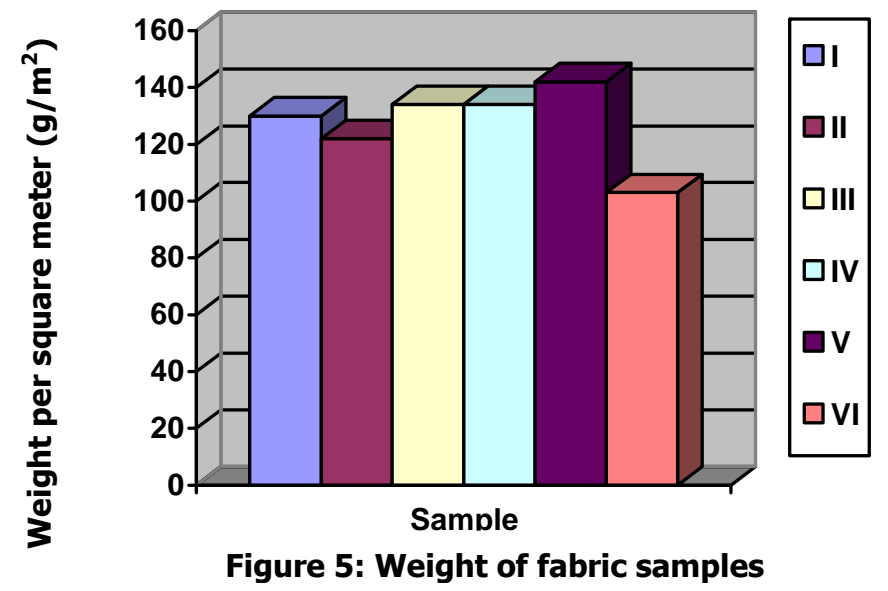

Comparing Figure 5 with Tables 3 and 4, it can be inferred that sample $\mathrm{V}$ is heavier in terms of material content, firmer in terms of fabric density, and finer in terms of yarn count, thus better than even the foreign fabrics. However, samples I, III, \& IV showed similar characteristics in terms of fabric area density.

The relatively low weight per square meter of sample II may be partly responsible for its better drapeability

\section{Fabric Drape}

Fabric drape is the extent to which a fabric will deform, when it is allowed to hang under its own weight. It is largely affected by the yarn twist. The drape coefficient expresses the drapeability of the fabric, and the higher the value of drape coefficient, the poorer its drapeability. 


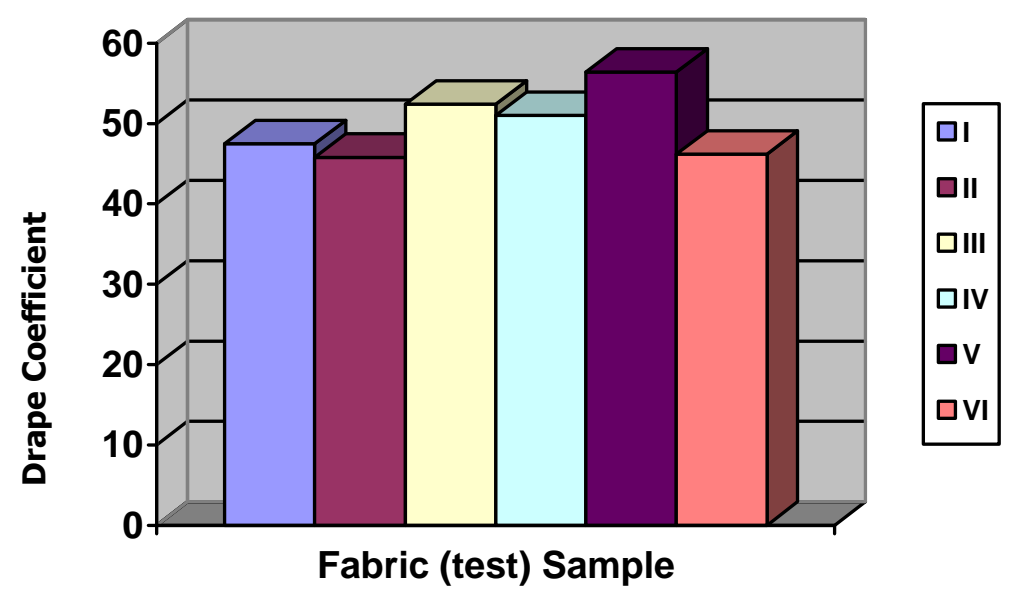

Figure 6 showed that sample $V$ is the stiffest which could be attributed to its higher fabric density and probably higher yarn twist. Sample II is the smoothest with the list drape coefficient, and will therefore assume a graceful appearance in use.

\section{Tensile Strength (Braking load)}

Breaking load is often defined as the maximum load applied to a specimen in stretching it to rupture, and the extension at this breaking load is referred to as the breaking extension. The strength of the yarn and other additional effects due to fabric structure determines the breaking load of the fabric in either warp or weft direction.

Figure 7 shows the breaking load of the six samples being investigated and Figure. 8 the corresponding extensions at break. It may be observed that generally

\section{bric Drape}

the warp yarns are stronger than the weft yarns in each sample, this indeed is expected since the warp yarns under go greater stresses particularly during weaving processes than the weft yarns.

The results also shows that the weft are more elastic than the warp for individual samples, this is attributed to the sizing and desizing processes the warp yarns were subjected during the production processes, in addition to other factors that affect the yarn and the fabric tensile properties.

Figure 7 showed that there is a slight difference in the breaking load of the six fabric samples, which may obviously be attributed to the variations in the strength of the yarns components in the individual samples.

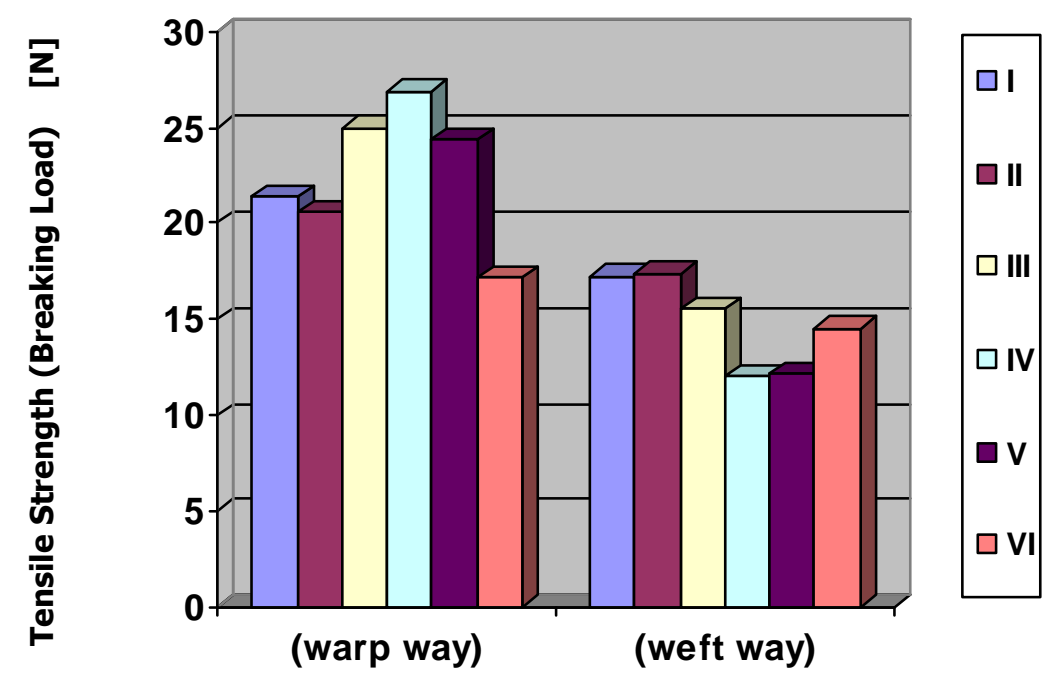

Figure 7: Stress at break

\section{Fabric (test) sample}




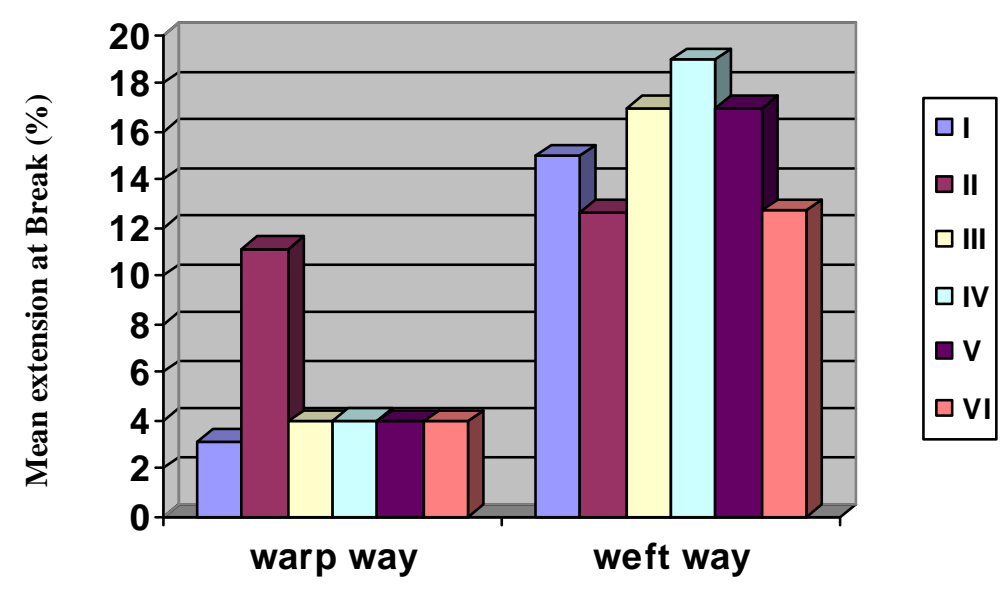

Fabric (test) sample
Figure 7: Stress at break

\section{Fabric Flammability}

It can be observed that sample (VI) is highly flammable, samples (II \& III) are flammable, while samples (I, IV and V) are flame proof self extinguishing. Thus, the local fabrics are shown to have better flammability ratings than the foreign ones.

Table 5: Fabric flammability

\begin{tabular}{lrl}
$\begin{array}{l}\text { TEST } \\
\text { SAMPLE }\end{array}$ & AVERAGE BURNING TIME & FLAMABILITY GRADE \\
(Seconds) & \\
\hline I & 12.56 & $\mathrm{D}$ \\
II & 6.24 & $\mathrm{~B}$ \\
III & 9.84 & $\mathrm{~B}$ \\
IV & 15.38 & $\mathrm{D}$ \\
V & 16.76 & $\mathrm{D}$ \\
VI & 5.93 & $\mathrm{~A}$ \\
\hline
\end{tabular}

\section{Water Resistance}

The results in Table 6 , obtained from a scale mock rain shower produced by pouring water through a spray nozzle. Samples (I, II, III, \& IV), gave a spray rating of 50, indicating wetting of about half of the sprayed surface. Sample (V), gave a spray rating of 75 which indicates that the sprayed surface is wetted only at small discrete areas, while sample (VI), gave a spray rating of ' 0 ' indicating a complete wetting of the whole sprayed surface, that is, it has very poor (low) water resistance.

Table 6: Water resistance

\begin{tabular}{ll}
\hline TEST SAMPLE & SPRAY RATING \\
\hline I & 50 \\
II & 50 \\
III & 50 \\
IV & 50 \\
V & 75 \\
VI & 0 \\
\hline
\end{tabular}

\section{Colour Fastness}

The resistance of a dye to agencies such as heat, water, light, soap, detergent mechanical action, as employed in domestic laundering according to Nkeonye ${ }^{4}$ is an important feature in the use of coloured textiles. This is because these are the major areas in which serviceability of coloured textiles are most important to customer. Colour fastness is therefore a major consideration by custormers when deciding what product to buy ${ }^{1}$. Observing results Table 6, there was no much differences between the foreign and the locally produced fabrics, this is because all the six samples showed remarkable fastness ratings on washing. However, sample (I) shows an exceptional wash fastness. 
Table 7: Wash fastness rating

\begin{tabular}{lll}
\hline TEST SAMPLE & $\begin{array}{l}\text { WASH FASTNESS RATING } \\
\text { CHANGE IN COLOUR }\end{array}$ & STAINING \\
\hline I & 5 & 5 \\
II & $4-5$ & 4 \\
III & $4-5$ & 5 \\
IV & $4-5$ & 5 \\
V & $4-5$ & 5 \\
VI & $4-5$ & 5 \\
\hline
\end{tabular}

\section{Fabric Handle}

Fabric handle deals with subjective ranking of fabric samples, in terms of appearance, aesthetics properties and comfort.

From the test carried out it was observed that different strokes for different folks in terms of their individual judgment when they felled the fabric with their hands.

The results rating were largely in favour of the foreign fabrics in the following order.

$$
\text { I }>\text { II }>\text { IV }>\text { III }>\text { V > VI }
$$

The sense of judgment varied among softness, thickness, fading, comfort, smoothness, and coarseness. Also the colours of textile fabrics influenced this test.

\section{REFERENCES}

Raji, O. K; Chima, J. F. and Adamu, S. U (2007). A comparative study of selected properties of Nigerian and Foreign made Wax printed Textiles. A conference paper, presented at the $9^{\text {th }}$ annual conference of the National Science and Technology forum. Held at Banquet hall, Kaduna Polytechnic Kaduna, Nigeria. $29^{\text {th }}$ October $-2^{\text {nd }}$ November 2007.

British Standard Handbook (1974), British Standard Institute. $\{4 /(1-224)\}$

Danfulani, E.(2006). Comparative Analysis of some local and foreign fabrics in Nigeria. A final year project presented to the department of Textile Science and Technology, Ahmadu Bello University, Zaria. Nigeria.

Nkeonye, P. O. (1987). Fundamental Principles of Textile Dyeing, Printing and Finishing.

\section{Conclusion}

From the investigation carried out, $z$ it can be said that the locally produced fabrics are comparably similar to the foreign fabrics in terms of durability, tensile strength, colour fastness and comfortability (especially the air permeability), considering the nature of this environment. However, it is deficient in terms of dimensional stability, aesthetic properties and crease recovery as compared to the foreign materials. Aesthetic property and fabric handle are more of subjective assessments therefore, other factors such as psychological belief may influence individuals.

Ahmadu Bello University Press Ltd. Zaria. Nigeria.

Omar, B. B. (2006). Air permeability \& Porosity in Spun-laced Fabrics. Fibres \& Textiles in Eastern Europe 14 3(57) 81-85

Booth, J. E. (1968). Principles of textile testing, $3^{\text {rd }}$ edition. Butterworth and Co. London.

Booth, J. E. (1974). Principles of textile testing, $3^{\text {rd }}$ edition. Butterworth publication. (255 - 444).

Encyclopedia of Chemical Technology, (1980) $2^{\text {nd }}$ edition. J. Wiley $20(36-48)$.

Groover, H (1960), Handbook of Textile and Quality control John Wiley and sons, New York, (523 $-535)$.

Koblyakov, A. (1987). Laboratory Practice in study of textile materials. MIR publishers, Moscow. (271 - 364). 